\title{
Identification of the Glimepiride and Metformin Hydrochloride Physical Interaction in Binary Systems
}

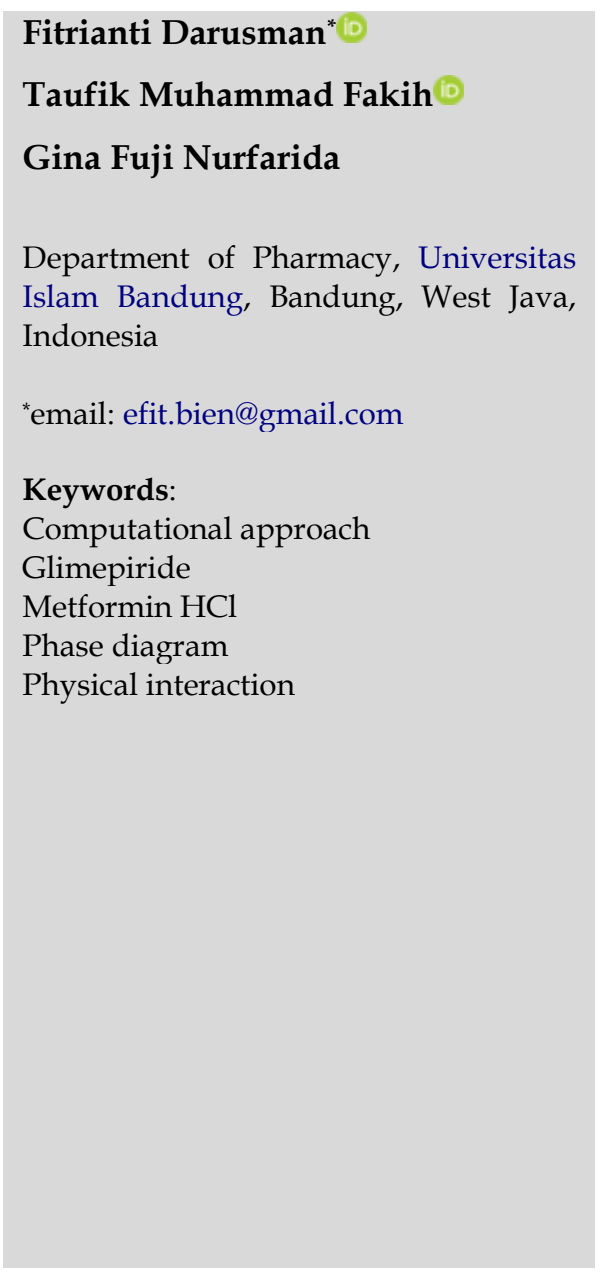

\begin{abstract}
Glimepiride is often combined with metformin $\mathrm{HCl}$ as an oral antidiabetic in type II diabetes mellitus, which provides a complementary and synergistic effect with multiple targets for insulin secretion. Glimepiride includes class II of BCS, which solubility practically insoluble in water but high permeability, which will impact the drug's small bioavailability. In contrast, metformin $\mathrm{HCl}$ includes class III of BCS, which has a high solubility in water, but low permeability is absorbed approximately $50-60 \%$ in the digestive tract given orally. The co-crystallization method can be used to improve the glimepiride solubility properties and the permeability properties of metformin $\mathrm{HCl}$ by interrupting glimepiride with metformin $\mathrm{HCl}$ physically. This study aims to identify the physical interactions between glimepiride and metformin HCL using a thermal analysis of Differential Scanning Calorimetry (DSC) and then confirmed by a computational approach. Identifying the physical interactions between glimepiride and metformin HCL was carried out by plotting the melting points generated from the endothermic peaks of the DSC thermogram at various compositions versus the mole ratios of the two were further confirmed by the computational approach using PatchDock. The results of the phase diagram analysis of the binary system between glimepiride and metformin $\mathrm{HCl}$ show a congruent pattern, which indicates the formation of co-crystal or molecular compounds at a $1: 1$ mole ratio at $228^{\circ} \mathrm{C}$. Computational approach results showed that the interaction between glimepiride and metformin $\mathrm{HCl}$ did not form new compounds but heterosinton formation that was stable in molecular dynamics simulations.
\end{abstract}

Received: November $15^{\text {th }}, 2020$

Accepted: March 6th, 2021

Published: May 30th, 2021

(c) 2021 Fitrianti Darusman, Taufik Muhammad Fakih, Gina Fuji Nurfarida. Published by Institute for Research and Community Services Universitas Muhammadiyah Palangkaraya. This is an Open Access article under the CC-BY-SA License (http://creativecommons.org/licenses/by-sa/4.0/). DOI: https:// doi.org/10.33084/ bjop.v4i2.1826

\section{INTRODUCTION}

Glimepiride (GMP) is often combined with metformin $\mathrm{HCl}$ (MET) as an oral antidiabetic in type II diabetes mellitus (T2DM), which provides complementary and synergistic effects with the dual goal of improving insulin secretion and insulin action in tissues ${ }^{1}$. Glimepiride includes in biopharmaceutics classification system (BCS) class II, which has low solubility but high permeability with practically insoluble solubility data in water, so that it will have an impact on the small bioavailability of the drug. In contrast, MET includes in BCS class III, which has a high solubility in water, but has low permeability, which is about $50-60 \%$ absorbed in the gastrointestinal tract given orally ${ }^{2,3}$.

Sanofi Aventis has produced GMP and MET in a fixeddose combination (Amaryl $\mathrm{M} \AA$ ) tablet dosage form, which is an innovator product ${ }^{4}$. However, some pharmaceutical manufacturers that make copy product of GMP and MET are constrained in producing tablet 
preparations that meet quality requirements so that efforts need to be made to increase the solubility of GMP as well as the permeability of MET by physically interacting GMP with MET through the cocrystallization method ${ }^{5,6}$. Cocrystallization is a physical method based on the combination of active pharmaceutical ingredients acting as a host with co-formers acting as guests through hydrogen bonds or Van der Waals in the same crystal lattice ${ }^{78}$.

Studies on the identification of the type of interaction between GMP and MET have not been previously reported. For this reason, it is necessary to identify the physical interactions that occur between GMP and MET using thermal analysis differential scanning calorimetry (DSC), the results of which are then constructed in the form of a phase diagram of the GMP-MET binary system $^{9,10}$. Furthermore, the resulting physical interactions were confirmed by the computational approach using docking simulations methods, molecular dynamics simulations, and MM/PBSA binding-free energy calculations ${ }^{11,12}$.

\section{MATERIALS AND METHODS}

\section{Materials}

The material used were glimepiride (Glenmark, India) and metformin hydrochloride (Hildose, India). The instruments used include DSC-Thermogravimetric analysis (DSC-TGA STA PT1600, LINSEIS Thermal Analysis), analytical scales (Mettler Toledo AG204), vortex mixer (JEIO Tech) and microtube (Eppendorf). The in silico study was conducted with a computer with an Intel® Core i3-6100 CPU @ 2.30 GHz (4 CPUs) specification, 4096 MB RAM, 320 GB hard drive, and VGA Intel HD Graphics 520. The software used includes Quantum ESPRESSO v.6.6, PatchDock web server (https://bioinfo3d.cs.tau.ac.il/PatchDock/php.php),
Gromacs 2016.3, VMD 1.9.4, and BIOVIA Discovery Studio Visualizer v16.1.0.15350.

\section{Methods}

\section{Molecular structure modeling and optimization}

The molecular structure of GMP and MET was modeled in two-dimensional using the BIOVIA Discovery Studio Visualizer v16.1.0.15350, which downloaded from the PubChem website in National Center for Biotechnology Information (https://pubchem.ncbi.nlm.nih.gov/) as shown in Figure 1. Optimization of the molecular structure of the GMP and MET was performed using the Quantum ESPRESSO v.6.6 with density functional theory (DFT) B3LYP method based on the 3-21G set ${ }^{13}$.

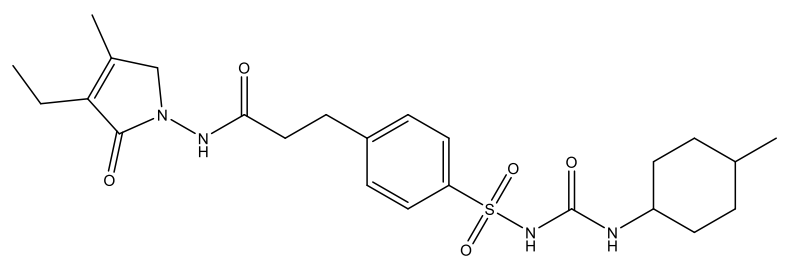

a

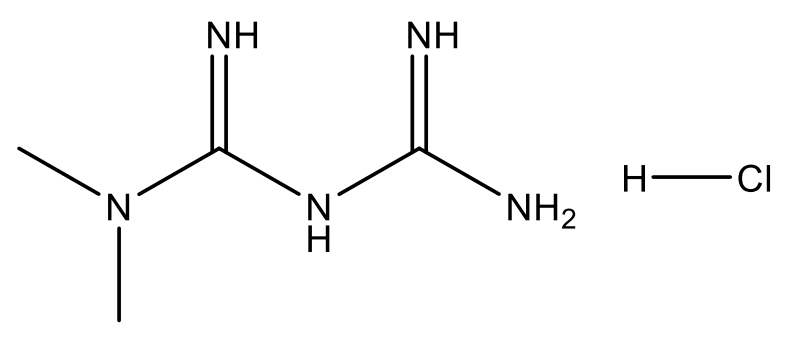

b

Figure 1. The two-dimensional structure of (a) GMP and (b) MET

\section{Glimepiride-metformin complex formation simulations}

The optimized GMP and MET compounds were then simulated for complex formation. This complex formation simulation was accomplished using the PatchDock web server according to the procedure reported by Fakih et al ${ }^{15}$.

\section{Identification of glimepiride-metformin interactions}

The molecular interactions formed between GMP and MET molecules were then identified using the BIOVIA 
Discovery Studio Visualizer v16.1.0.15350 according to the procedure reported by Fakih et $a l^{15}$.

\section{Glimepiride-metformin interaction dynamics}

Interaction dynamics simulations were performed using Gromacs 2016.3 to observe and identify the stability of GMP and MET. Electrostatic forces were selected using the Particle Mesh Ewald method. Neutralization of the system was carried out by adding $\mathrm{Na}^{+}$and $\mathrm{Cl}^{-}$ions. Solvation was determined using the TIP3P water model. The simulation preparation stage includes minimization, heating to $310 \mathrm{~K}$, temperature equilibration, pressure equilibration, and a $500 \mathrm{~ns}$ production run with a $2 \mathrm{fs}$ timestep $\mathrm{p}^{15,16}$.

\section{MM/PBSA end-point binding-free energy calculations}

The Molecular Mechanics/Poisson-Boltzmann Surface Area (MM/PBSA) binding-free energy calculations were accomplished by the g_mmpbsa package integrated into the Gromacs 2016.3. The polar desolvation energy was calculated using the Poisson-Boltzmann equation with a grid size of $0.5 \AA$. The dielectric constant of the solvent was set to 80 to represent water as the solvent. The nonpolar contribution was determined by calculating the surface area accessible to the solvent with a radius of 1.4 $\AA^{17-19}$.

\section{Preparation of glimepiride-metformin physical mixtures}

Preparation of the physical mixture of GMP-MET was carried out by weighing GMP and MET at various compositions based on the mole ratio between the two, which was carried out for three replications. It was known that the molecular weights of GMP and MET were $490.62 \mathrm{~g} / \mathrm{mol}$ and $165.63 \mathrm{~g} / \mathrm{mol}$, respectively. Furthermore, thermal analysis was carried out using the DSC method to obtain the melting point of the endothermic peak of the DSC thermogram, which was constructed into a phase diagram of the GMP-MET binary system ${ }^{21}$.

\section{RESULTS AND DISCUSSION}

Glimepiride-metformin binary mixtures

Preparation of the GMP-MET binary mixture aims to identify the interactions between GMP and MET at various compositions based on their molecular ratios, whether the cocrystal phase (molecular compound) or a simple eutectic mixture was formed as well as its molecular ratio, as shown in Table I. This binary mixture was thermally analyzed using the DSC method so that the melting point from the endothermic peak of the DSC thermogram was obtained, as presented in Table II. Then, it was constructed into a binary system phase diagram by plotting the resulting melting points of the endothermic peak of the DSC GMP-MET thermogram at various compositions versus the mole ratio of the two, as presented in Figure 2.

The results of the phase diagram analysis of the GMPMET binary system show a congruent pattern that indicates the formation of cocrystal or molecular compounds. The physical mixture of GMP-MET showed this phenomenon at a mole ratio of $1: 1$ (GM 7), which had two endothermic peaks at a temperature of $196.6^{\circ} \mathrm{C}$ and $228^{\circ} \mathrm{C} .228^{\circ} \mathrm{C}$ was the highest melting temperature between the melting temperatures of GMP and MET of pure forms were $205.8^{\circ} \mathrm{C}$ and $235.1^{\circ} \mathrm{C}$, respectively ${ }^{22}$. If the two components form the compound of molecular, it would be flanked by two temperature melting compound called eutectic point $\left(\mathrm{T}_{\mathrm{E}}\right), \mathrm{T}_{\mathrm{A}}$ and $\mathrm{T}_{\mathrm{B}}$ was the melting temperature of each pure components of GMP and MET, when the temperature was plotted based on the composition of the mixture of components would be obtained a $\mathrm{T}_{\mathrm{A}}-\mathrm{T}_{\mathrm{E}}-\mathrm{T}_{\mathrm{C}}-\mathrm{T}_{\mathrm{E}}-\mathrm{T}_{\mathrm{B}}$ track called the liquidus curve. Above the liquidus curve, GMP and MET were in the liquid phase, and the two components of the compound dissolve with each other ${ }^{22,23}$.

The highest melting point was $\mathrm{T}_{\mathrm{C}}$ of the liquidus curve, which was the point of formation of molecular 
compounds, while the lowest melting point is $\mathrm{T}_{\mathrm{E}}$ of the liquidus curve, which was the eutectic point. At $\mathrm{T}_{\mathrm{C}}$ point, two components, $\mathrm{A}$ and $\mathrm{B}$, were melted together (congruent) without changing the composition of the two components at the same highest temperature and the liquid phase was in equilibrium with the solid phase. Under the liquidus curve, each component A and B was in a solid state and did not dissolve in one another ${ }^{25}$.

Whereas in the GMP-MET physical mixture, the mole ratio of $1: 9$ (GM3), 2:8 (GM4), and 3:7 (GM5) also had two endothermic peaks, in which the melting temperature at the second endothermic peak was lower than the physical mixture GMP-MET mole ratio was 1 : 1 (GM 7). Therefore, it was not a point of formation of molecular or cocrystal compounds, but this phenomenon was only partial, meaning that the physical mixture of GMP-MET in these three ratios did not melt together ${ }^{26}$.

Table I. Composition of the GMP-MET binary mixture

\begin{tabular}{|c|c|c|c|c|}
\hline \multirow{2}{*}{$\begin{array}{c}\text { Sample } \\
\text { Code }\end{array}$} & \multirow{2}{*}{$\begin{array}{c}\text { Mole } \\
\text { ratio } \\
\text { (GMP : } \\
\text { MET) }\end{array}$} & \multicolumn{3}{|c|}{ Weight (mg) } \\
\hline & & GMP & MET & GMP-MET \\
\hline GM 1 & $1: 0$ & 490.62 & 0 & 490.62 \\
\hline GM 2 & $0: 1$ & 0 & 165.63 & 165.63 \\
\hline GM 3 & $1: 9$ & 490.62 & 1490.67 & 1981.29 \\
\hline GM 4 & $2: 8$ & 981.24 & 1325.04 & 2306.28 \\
\hline GM 5 & $3: 7$ & 1471.86 & 1159.41 & 2631.27 \\
\hline GM 6 & $4: 6$ & 1962.48 & 993.78 & 2956.26 \\
\hline GM 7 & $5: 5$ & 2453.1 & 828.15 & 3281.25 \\
\hline GM 8 & $6: 4$ & 2943.72 & 662.52 & 3606.24 \\
\hline GM 9 & $7: 3$ & 3434.34 & 496.89 & 3931.23 \\
\hline GM 10 & $8: 2$ & 3924.96 & 331.26 & 4256.22 \\
\hline GM 11 & $9: 1$ & 4415.58 & 165.63 & 4581.21 \\
\hline
\end{tabular}

Table II. Melting point recapitulation of the endothermic peak of the DSC thermogram GMP-MET binary mixture

\begin{tabular}{cccc}
\hline Sample & Mole ratio & \multicolumn{2}{c}{ Melting point $\left({ }^{\circ} \mathbf{C}\right)$} \\
\cline { 3 - 4 } Code & (GMP : MET) & $\mathbf{1}$ & $\mathbf{2}$ \\
\hline GM 1 & $1: 0$ & 205.8 & - \\
GM 2 & $0: 1$ & 235.1 & - \\
GM 3 & $1: 9$ & 191.2 & 223.6 \\
GM 4 & $2: 8$ & 197.9 & 218.4 \\
GM 5 & $3: 7$ & 201.8 & 216.2 \\
GM 6 & $4: 6$ & 194.4 & - \\
GM 7 & $5: 5$ & 196.6 & 228 \\
GM 8 & $6: 4$ & 195.7 & - \\
GM 9 & $7: 3$ & 186.4 & - \\
GM 10 & $8: 2$ & 198.7 & - \\
GM 11 & $9: 1$ & 201.5 & - \\
\hline
\end{tabular}

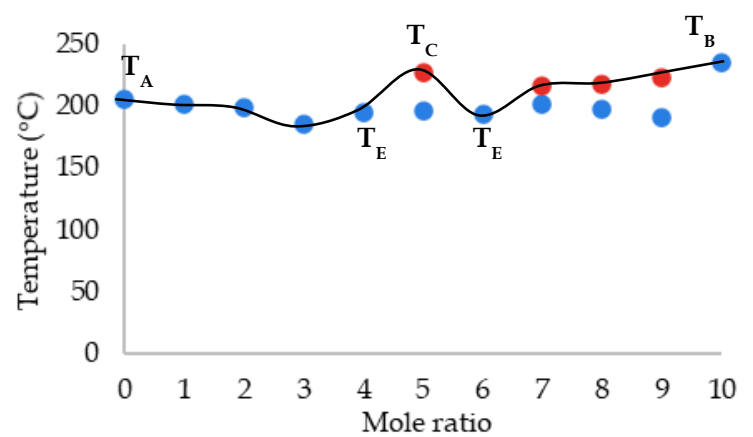

Figure 2. Phase diagram of GMP-MET binary systems. $\mathrm{T}_{\mathrm{A}}$ : Melting point of GMP; $\mathrm{T}_{\mathrm{B}}$ : Melting point of MET; $\mathrm{TC}_{\mathrm{C}}$ Cocrystal point; $\mathrm{T}_{\mathrm{E}}$ : Eutectic point.

Mole ratio: $0=$ GMP $: \operatorname{MET}(1: 0) ; 1=$ GMP $:$ MET (9:1); $2=$ GMP $:$ MET (8:2);3=GMP:MET (7:3); = GMP:MET (6:4);5= GMP:MET (5:5); $6=$ GMP $:$ MET (4:6);7=GMP:MET (3:7);8=GMP:MET (2:8);9= GMP:MET $(1: 9) ; 10=$ GMP:MET $(0: 1)$

\section{Computational approach of glimepiride-metformin}

The computational approach was demonstrated to identify and confirm the physical interactions between GMP and MET. Figure 3 shows that the interaction between GMP and MET did not form new compounds. However, the interaction that occurs was the formation of hydrogen bonds with heterosinton formation (Table III), as well as Van der Waals bonds were minimal, with a total energy of $-0.00096 \AA$ and a binding-free energy value of $-415.35 \mathrm{~kJ} / \mathrm{mol}$. This binding-free energy produces a negative value which indicates a physical interaction between GMP and MET compounds that occurred spontaneously ${ }^{27}$.

Overall poses of GMP and MET complexes changed during the simulation. However, based on the snapshots taken at 125, 250, 375, and $500 \mathrm{~ns}$ from the molecular dynamics simulation results, only slight conformational changes were observed (Figure 4). It was predicted that this phenomenon would increase the ability of the GMP and MET to interact with the active site of the target receptor ${ }^{28}$. 

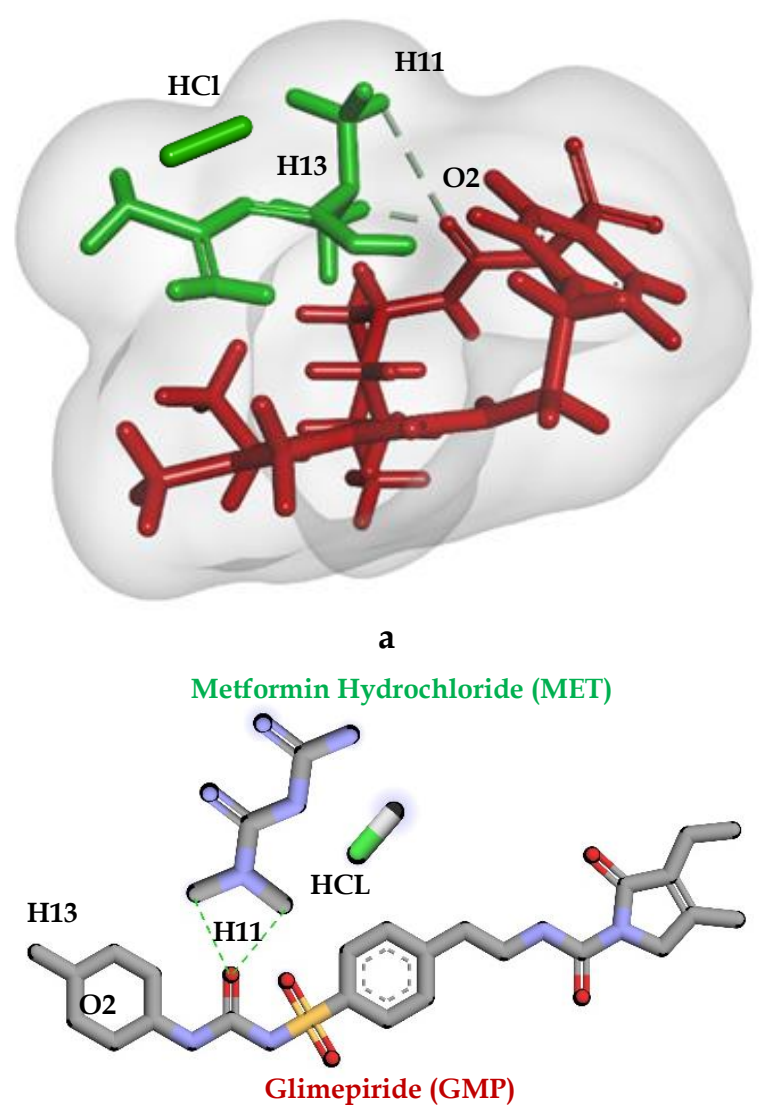

b

Figure 3. The three-dimensional (a) and two-dimensional (b) interaction of GMP and MET in docking simulations

Table III. Interaction between GMP and MET from docking simulations

\begin{tabular}{cccc}
\hline $\begin{array}{c}\text { Glimepiride } \\
\text { atom }\end{array}$ & $\begin{array}{c}\text { Metformin } \\
\text { atom }\end{array}$ & $\begin{array}{c}\text { Distance of } \\
\text { interaction }(\AA)\end{array}$ & $\begin{array}{c}\text { Type of } \\
\text { interation }\end{array}$ \\
\hline Oxygen $(\mathrm{O} 2)$ & $\begin{array}{c}\text { Hydrogen } \\
\text { (H11) }\end{array}$ & 2.98128 & $\begin{array}{c}\text { Hydrogen } \\
\text { Bond }\end{array}$ \\
Oxygen (O2) & $\begin{array}{c}\text { Hydrogen } \\
\text { (H13) }\end{array}$ & 1.89064 & $\begin{array}{c}\text { Hydrogen } \\
\text { Bond }\end{array}$ \\
\hline
\end{tabular}

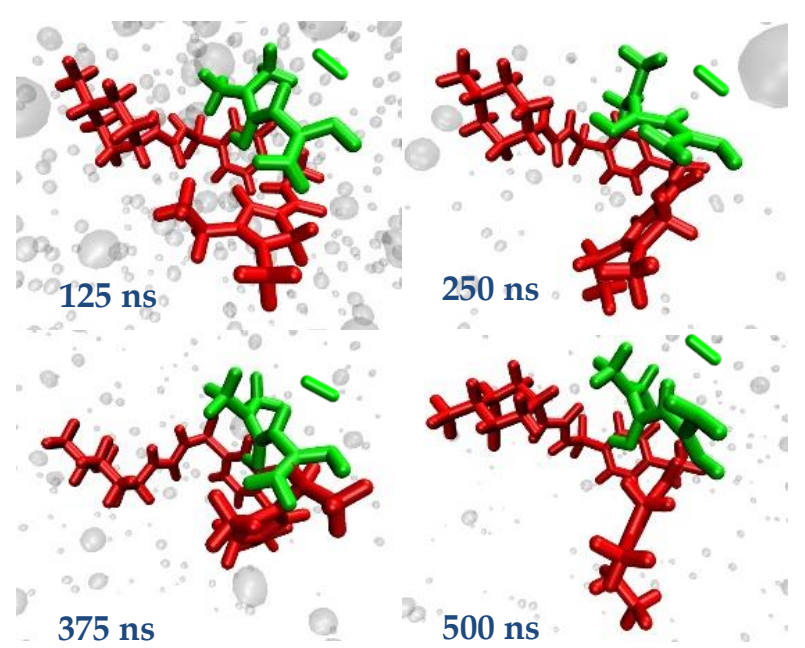

Figure 4. GMP (red) and MET (green) conformation snapshots at $125,250,375$, and $500 \mathrm{~ns}$
The root-mean-square deviation (RMSD) values of GMP and MET were calculated to ensure the stability and rationality of the selected conformations. Figure 5 shows that the complex formed fluctuates from 0 ns until 100 and 300 ns. Nevertheless, at the end of the complex simulation, the GMP and MET began to achieve stability $^{29}$. The average RMSD value during the molecular dynamics simulation was in the range of 2.04 A.

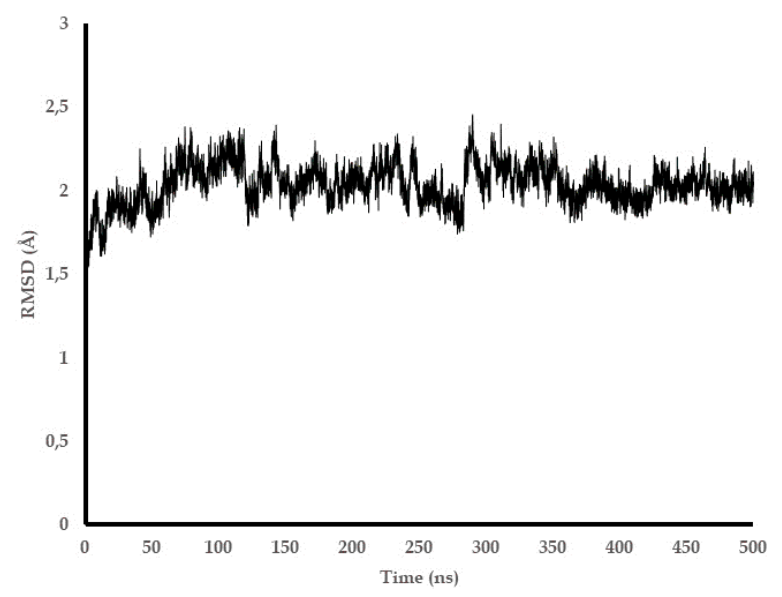

Figure 5. RMSD value during molecular dynamics simulation

The MM/PBSA free-binding energy was calculated based on the trajectory from the beginning to the end of the molecular dynamics simulation. Based on the MM/PBSA calculation results, it could be observed that the complex system had good binding-free energy, with a value of $-107.74 \mathrm{~kJ} / \mathrm{mol}$ (Table IV). The energies that contribute the most during the simulation were Van der Waals and electrostatic interactions. This was because the MM/PBSA approach allows observation of the influence of the contribution of Van der Waals and electrostatic and conformational changes that were influenced by the solvation process $^{29}$.

Table IV. Binding-free energy calculation from MM/PBSA

\begin{tabular}{ccccc}
\hline $\begin{array}{c}\Delta \mathbf{E}_{\mathrm{VdW}} \\
\mathbf{( k J} / \mathbf{m o l})\end{array}$ & $\begin{array}{c}\Delta \mathbf{E}_{\text {ele }} \\
\mathbf{( k J} / \mathbf{m o l})\end{array}$ & $\begin{array}{c}\Delta \mathbf{G}_{\mathrm{PB}} \\
\mathbf{( k J} / \mathbf{m o l})\end{array}$ & $\begin{array}{c}\Delta \mathbf{G}_{\mathrm{NP}} \\
\mathbf{( k J / m o l})\end{array}$ & $\begin{array}{c}\Delta \mathbf{G}_{\text {Bind }} \\
\mathbf{( k J} / \mathbf{m o l})\end{array}$ \\
\hline-125.03 & -37.45 & 66.78 & -12.04 & -107.74 \\
\hline
\end{tabular}

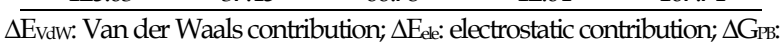
polar contribution of desolvation; $\Delta \mathrm{G}_{\mathrm{N}}$ : non-polar contribution of desolvation; $\Delta \mathrm{G}_{\mathrm{Bind}}: \Delta \mathrm{E}_{\mathrm{VdW}}+\Delta \mathrm{E}_{\mathrm{ele}}+\Delta \mathrm{G}_{\mathrm{PB}}+\Delta \mathrm{G}_{\mathrm{NP}}$ 


\section{CONCLUSION}

The identification results showed the presence of a cocrystal (molecular compound) interaction of glimepiridemetformin $\mathrm{HCl}$ at a $1: 1$ mole ratio and the formation of hydrogen bonds with heterosinton formation from docking simulations results which showed in bindingfree energy of $-415.35 \mathrm{~kJ} / \mathrm{mol}$. Especially, the complex system is stable in molecular dynamics simulations with an average RMSD value of $2.04 \AA$ and a calculated MM/PBSA value of $-107.74 \mathrm{~kJ} / \mathrm{mol}$.

\section{ACKNOWLEDGMENT}

The author would like to thank the Research Laboratory, Department of Pharmacy, Faculty of Mathematics and Natural Sciences, Universitas Islam Bandung for providing all the facilities in carrying out this research.

\section{AUTHORS' CONTRIBUTION}

Fitrianti Darusman: conceptualization, data curation, formal analysis, funding acquisition, investigation, methodology, project administration, resources, software, supervision, validation, visualization, writing original draft, and writing - review \& editing; Taufik Muhammad Fakih: data curation, formal analysis, investigation, resources, software, supervision, validation, visualization, writing - original draft, and writing - review \& editing; Gina Fuji Nurfarida: investigation, methodology, project administration, resources, software, and writing - original draft.

\section{DATA AVAILABILITY}

All data are available from the authors.

\section{CONFLICT OF INTEREST}

There are no conflicts of interest.

\section{REFERENCES}

1. Chaudhury A, Duvoor C, Dendi VSR, Kraleti S, Chada A, Ravilla R, et al. Clinical Review of Antidiabetic Drugs: Implications for Type 2 Diabetes Mellitus Management. Front Endocrinol. 2017;8:6. doi:10.3389/fendo.2017.00006

2. Bian X, Jiang L, Gan Z, Guan X, Zhang L, Cai L, et al. A Glimepiride-Metformin Multidrug Crystal: Synthesis, Crystal Structure Analysis, and Physicochemical Properties. Molecules. 2019;24(20):3786. doi:10.3390/molecules24203786

3. Mady OY, Donia AA, Al-Shoubki AA, Qasim W. Paracellular Pathway Enhancement of Metformin Hydrochloride via Molecular Dispersion in Span 60 Microparticles. 2019;10:713. doi:10.3389/fphar.2019.00713

4. Ahmed R. A simple and convenient method for the simultaneous in vitro study of metformin and glimepiride tablets. Pak J Pharm Sci. 27(6):1939-43.

5. Emami S, Siahi-Shadbad M, Adibkia K, BarzegarJalali M. Recent advances in improving oral drug bioavailability by cocrystals. Bioimpacts. 2018;8(4):305-20. doi:10.15171/bi.2018.33

6. Thayyil AR, Juturu T, Nayak S, Kamath S. Pharmaceutical Co-Crystallization: Regulatory Aspects, Design, Characterization, and Applications. Adv Pharm Bull. 2020;10(2):203-12. doi:10.34172/apb.2020.024

7. Yadav AV, Shete AS, Dabke AP, Kulkarni PV, Sakhare SS. Co-Crystals: A Novel Approach to Modify Physicochemical Properties of Active Pharmaceutical Ingredients. Indian J Pharm Sci. 2009;71(4):359-70. doi:10.4103/0250-474X.57283

8. Karagianni A, Malamatari M, Kachrimanis K. Pharmaceutical Cocrystals: New Solid Phase Modification Approaches for the Formulation of APIs. $\quad$ Pharmaceutics. 2018;10(1):18. doi:10.3390/pharmaceutics10010018

9. Medarević D, Ibrić S, Vardaka E, Mitrić M, Nikolakakis I, Kachrimanis K. Insight into the Formation of Glimepiride Nanocrystals by Wet Media Milling. Pharmaceutics. 2020;12(1):53. doi:10.3390/pharmaceutics12010053

10. Yamashita H, Hirakura Y, Yuda M, Teramura T, Terada K. Detection of cocrystal formation based on binary phase diagrams using thermal analysis. 
Pharm Res. 2013;30(1):70-80. doi:10.1007/s11095-0120850-1

11. Pagadala NS, Syed K, Tuszynski J. Software for molecular docking: a review. Biophys Rev. 2017;9(2):91-102. doi:10.1007/s12551-016-0247-1

12. Poli G, Granchi C, Rizzolio F, Tuccinardi T. Application of MM-PBSA Methods in Virtual Screening. Molecules. 2020;25(8):1971. doi:10.3390/molecules25081971

13. Giannozzi P, Baroni S, Bonini N, Calandra M, Car R, Cavazzoni $\mathrm{C}$, et al. QUANTUM ESPRESSO: a modular and open-source software project for quantum simulations of materials. J Phys Condens Matter. 2009;21(39):395502. doi:10.1088/0953$8984 / 21 / 39 / 395502$

14. Fakih TM, Dewi ML, Syahroni E. Magainin as an Antiviral Peptide of SARS-CoV-2 Main Protease for Potential Inhibitor: An In Silico Approach. Biogenesis Jurnal Ilmiah Biologi. 2020;8(1):104-10. doi:10.24252/bio.v8i1.13871

15. Fakih TM, Dewi ML, Syahroni E. Prediksi Stabilitas Mucroporin sebagai Kandidat Obat Berbasis Peptida melalui Simulasi Dinamika Molekular. JSFK (Jurnal Sains Farmasi \& Klinis). 2020;7(3):210-7. doi:10.25077/jsfk.7.3.210-217.2020

16. Muttaqin FZ, Fakih TM, Muhammad HN. Molecular Docking, Molecular Dynamics, and In Silico Toxicity Prediction Studies of Coumarin, N-Oxalylglycine, Organoselenium, Organosulfur, and Pyridine Derivatives as Histone Lysine Demethylase Inhibitors. Asian J Pharm Clin Res. 2017;10(12):212-5. doi:10.22159/ajpcr.2017.v10i12.19348

17. Wang E, Sun H, Wang J, Wang Z, Liu H, Zhang JZH, et al. End-Point Binding Free Energy Calculation with MM/PBSA and MM/GBSA: Strategies and Applications in Drug Design. Chem Rev. 2019;119(16):9478-508.

doi:10.1021/acs.chemrev.9b00055

18. Kartasasmita RE, Kurniawan F, Amelia T, Dewi CM, Harmoko, Pratama Y. Determination of Anthraquinone in Some Indonesian Black Tea and Its Predicted Risk Characterization. ACS Omega. 2020;5(32):20162-9. doi:10.1021/acsomega.0c01812

19. Kurniawan F, Miura Y, Kartasasmita RE, Mutalib A, Yoshioka N, Tjahjono DH. In Silico Study, Synthesis, and Cytotoxic Activities of Porphyrin Derivatives.
Pharmaceuticals.

2018;11(1):8. doi:10.3390/ph11010008

20. Rycerz L. Practical remarks concerning phase diagrams determination on the basis of differential scanning calorimetry measurements. J Therm Anal Calorim. 2013;113:231-8. doi:10.1007/s10973-0133097-0

21. Sekhon BS. Pharmaceutical co-crystals-a review. Ars Pharm. 2009;50(3):99-117.

22. Alhadid A, Mokrushina L, Minceva M. Modeling of Solid-Liquid Equilibria in Deep Eutectic Solvents: A Parameter Study. Molecules. 2019;24(12):2334. doi:10.3390/molecules24122334

23. Vippagunta SR, Wang Z, Hornung S, KrillSL. Factors affecting the formation of eutectic solid dispersions and their dissolution behavior. J Pharm Sci. 2007;96(2):294-304. doi:10.1002/jps.20754

24. Healy AM, Worku ZA, Kumar D, Madi AM. Pharmaceutical solvates, hydrates and amorphous forms: A special emphasis on cocrystals. Adv Drug Deliv Rev. 2017;117:25-46. doi:10.1016/j.addr.2017.03.002

25. Kuminek G, Cao F, da Rocha ABdO, Cardoso SG, Rodríguez-Hornedo $\mathrm{N}$. Cocrystals to facilitate delivery of poorly soluble compounds beyond-ruleof-5. Adv Drug Deliv Rev. 2016;101:143-66. doi:10.1016/j.addr.2016.04.022

26. Pinzi L, Rastelli G. Molecular Docking: Shifting Paradigms in Drug Discovery. Int J Mol Sci. 2019;20(18):4331. doi:10.3390/ijms20184331

27. Hu G, Ma A, Wang J. Ligand Selectivity Mechanism and Conformational Changes in Guanine Riboswitch by Molecular Dynamics Simulations and Free Energy Calculations. J Chem Inf Model. 2017;57(4):918-28. doi:10.1021/acs.jcim.7b00139

28. Liu K, Kokubo H. Exploring the Stability of Ligand Binding Modes to Proteins by Molecular Dynamics Simulations: A Cross-docking Study. J Chem Inf Model. doi:10.1021/acs.jcim.7b00412

29. Aldeghi M, Bodkin MJ, Knapp S, Biggin PC. Statistical Analysis on the Performance of Molecular Mechanics Poisson-Boltzmann Surface Area versus Absolute Binding Free Energy Calculations: Bromodomains as a Case Study. J Chem Inf Model. 2017;57(9):2203-21. doi:10.1021/acs.jcim.7b00347 